\title{
OCR HURUF JAWA DENGAN FITUR KODE RANTAI DAN LEVENSHTEIN DISTANCE
}

\author{
Teady Matius Surya Mulyana'), Destriana Widyaningrum²), Herlina ${ }^{3)}$ \\ 1), 2), 3) Program Studi Informatika, Fakultas Teknologidan Desain, Universitas Bunda Mulia \\ Jl Raya Lodan, nomor 2, Jakarta Utara \\ Email:tmulyana@bundamulia.ac.id ${ }^{1)}$,des3ana@gmail.com ${ }^{2}$, herlina@bundamulia.ac.id ${ }^{3)}$ \\ Corresponding author Phone: +6287782031728
}

\begin{abstract}
Abstrak
Aplikasi sederhana untuk pengenalan aksara jawa diperlukan pada saat massive nya penggunaan aksara nasional. Aplikasi diperlukan untuk mengenali dan membaca karakter-karakter dari aksara jawa pada pesan-pesan yang diterima. Fitur dan metode yang sederhana untuk mengenali aksara jawa sangat diperlukan sehingga aplikasi dapat sewaktu-waktu melakukan pelatihan, dimana data pelatihan yang disediakan sedikit. Salah satufitur sederhana yang tersedia adalah kode rantai. Permasalahannya adalah kode rantai merupakan untaian karakter, maka diperlukan pengukuran jarak yang sesuai, bukan pengukuran jarak yang umum digunakan pada OCR. Levenshtein Distance merupakan pengukuran jarak antara dua string. Sesuai dengan fitur yang dipilih, maka akan digunakan levenshtein distance untuk mengukur jarak dua buah kode rantai. Pada penelitian ini akan dibuktikan fitur kode rantai dengan pengukuran jarak menggunakan levenshtein distance mampu mengenali objek aksara jawa berdasarkan data pela tihan yang tersimpan. Metode klasifikasi yang dipergunakan adalah klasifikasinearest-neighbor. Dipilihnya metode ini dimaksudkan agar mampu memberi informasi data pelatihan yang terdekat dengan objek yang ingin dikenali. Hasilpenelitian menunjukkanfitur kode rantaidengan pengukuran jarakdengan levenshtein distance mampumengenalifitur datapelatihan yang terdekatdenganfitur objek.
\end{abstract}

Kata kunci: Aksara Jawa, kode rantai, Levenshtein Distance, OCR

\begin{abstract}
A simple application forthe introduction of Javanese characters is needed when the massive use of national characters is needed. Applications areneeded to recognize and read characters from Javanese characters in received messages. Simple features and methods to recognize Javanese characters are needed so that the application can do training at any time not too much training data. One of the simplerfeatures available is chain code. The problem is that the chain code is a string of characters, it requires an appropriate distance measurement, not the distance measurement commonly used in OCR. Levenshtein Distance is a measurement of the distance between two strings. In accordance with the selected feature, the levenshtein distance will be used to measure the distance of two chain codes. In this study, it will be proven that the chain code feature with distance measurement using levenshtein distance is able to recognize Javanese script objects based on stored training data. The classification method used is the nearest-neighbor classification. The choice of this method is intended to be able to provide training data information that is closest to the object you want to recognize. The results showed that the chain code feature with distance measurement with levenshtein distance was able to recognize the training data feature that was closest to the objectfeature.
\end{abstract}

Keywords : chain code, Javanese script, Levenshtein Distance, OCR.

\section{PENDAHULUAN}

Aksara jawa merupakan salah satu aksara daerah yang masih dipergunakan pada sejumlah daerah[1]. Pada daerah-daerah pariwisata di jawa tengah seringkali masih mencantumkan informasi situsnya menggunakan aksara jawa. Pelatihan-pelatihan menulis dan membaca aksara jawa menggunakan perangkat-perangkat lunak untuk keperluan sosial dan budaya sudah mulai dilakukan dilingkungan pendidikan[2][3]. Banyak pihak menyadari pemakaian aksara jawa dapat menaikkan gengsi suatu produk, salah satunya mampu menaikkan brand-image[4]. Masif nya pelatihan-pelatihan digitalisasi aksara jawa mengakibatkan banyak pesan-pesan dapat disampaikan dengan menggunakan aksara jawa pada berbagai media, salah satunya pada Tshirt[5], tetapi hal ini tidak diimbangi dengan kemampuan membaca aksara jawa. Ketimpangan 
ini mengakibatkan akan banyak pesan-pesan menjadi tidak berguna, karena hanya akan dapat dibaca sedikit orang saja.

Optical Character Recognizing (OCR) adalah suatu proses pengenalan karakter pada suatu citra menjadi teks. Salah satu pemanfaatan nya adalah pengenalan karakter huruf jawa. Pada beberapa pemakaian aplikasi OCR aksara Jawa, seringkali orang memerlukan pelatihan OCR dengan data yang seadanya, mengingat beberapa orang memerlukan aplikasi yang dapat segera dipergunakan. Aplikasi yang diperlukan tentu saja memerlukan pengumpulan data training yang sedikit bahkan seringkali tidak lengkap karakternya. Pendekatan OCR yang sering dilakukan adalah OCR dengan machine learning.

Penelitian terdahulu mengenai chaincode mempergunakan normalisasi terhadap chaincode. Penelitian tersebut diterapkan pada pengenalan rambu lalulintas[6]. Pada penelitian tersebut memang efektif untuk mengenali rambu lalulintas yang memiliki perbedaan tiap simbolnya. Metode normalisasi pada chaincode kurang memadai karena akan mengakibatkan semakin kecilnya jarak pada objek karakter yang berbeda, hal ini dikarenakan aksara jawa memiliki banyak kesamaan pada bagian atas dan bawah pada tiap karakternya.

Penelitian terdahulu yang lain dilakukan pada OCR dengan fitur chaincode dengan support vector machine memerlukan data yang lengkap dan banyak[7]. OCR dengan machine learning kurang memadai untuk pelatihan seperti ini[8][9][10]. Metode machine learning memerlukan data pelatihan untuk klasifikasi dengan jumlah kelas yang lengkap dan data training yang banyak untuk tiap kelasnya[11]. Sehingga diperlukan sebuah metode dan fitur yang mampu memfasilitasi pelatihan OCR pada program OCR yang lebih sederhana dengan jumlah data pelatihan yang lebih sedikit.

Penelitian terdahulu mengenai OCR aksara jawa dengan fitur chaincode pernah dilakukan dengan mempergunakan metode neural network[12]. Seperti yang sudah dibahas di atas, metode ini memerlukan data training yang lengkap dan banyak. Tujuan dari penelitian tersebut adalah akurasinya, sedangkan pada penelitian kali ini diharapkan kemudahan trainingnya.

Fitur chaincode terbentuk dari untaian kode rantai yang diekstrak dari sebuah objek garis berdasarkan kode arah. Objek garis yang dibentuk dari sebuah karakter pada penelitian ini diperbolehkan untuk bercabang. Agar dapat digunakan pada metode klasifikasi nearest neighbor, jarak antara dua chaincode dapat dicari menggunakan metode pencarian jarak antara dua buah string. Penelitian ini mempergunakan pengukuran jarak antara dua string menggunakan levenshtein distance. Penelitian ini dimaksudkan untuk membuktikan hipotesa bagaimana fitur chain code dengan metode pengukuran jarak mampu mengenali aksara jawa.

\section{DASAR TEORI}

OCR untuk aksara jawa banyak dilakukan dengan berbagai fitur dan metode[12][13]. Chain code merupakan suatu fitur yang cukup mudah ekstraksinya. Fitur chaincode terbentuk dari untaian kode rantai yang diekstrak dari sebuah objek garis berdasarkan kode arah[8]. Penerapan chaincode memerlukan presisi fitur yang tepat. Gangguan pada objek ataupun perbedaan sedikit pada objek akan membuat kedua objek akan dianggap berbeda[14]. Sehingga pada salah penelitian dilakukan metode normalisasi chain code dengan melakukan sorting pada hasil normalisasi histogram chain code[14][9]. Metode ini memerlukan usaha untuk penerapannya serta pelatihan yang panjang untuk dapat menghasilkan hasil OCR nya. Tentu saja metode ini kurang efektif jika diterapkan pada sebuah metode klasifikasi. Metode klasifikasi seperti seperti nearest Neighbor memerlukan toleransi terhadap perbedaan yang cukup tinggi.

Metode Nearest Neighbor mempergunakan jarak pada fitur[15][16][17][18]. Salah satu keuntungan penggunaan nearest Neighbor adalah tidak diperlukan data pelatihan yang lengkap terlebih dahulu. Kelas manapun yang dilatih dengan metode nearest neighbor, maka kelas tersebut dapat dipergunakan untuk mengenali karakter. Seperti halnya dengan k-Nearest Neighbor, klasifikasi Nearest Neighbor juga menggunakan jarak untuk mengukur kedekatan fitur antara satu objek dengan objek lainnya[19]. Pada kasus yang sederhana K-Nearest Neighbor dapat diterapkan dengan metode nearest neighbor dengan nilai $\mathrm{K}=1$ saja sehingga tidak 
memerlukan adanya statistik nilai terdekat pada suatu kelompok, tetapi cukup mencari nilai terdekat saja antara objek yang akan diklasifisikasikan dengan salah satu objek pada kelas yang tesedia.

Chain code merupakan untaian karakter dari kode rantai. Sebagai utaian karakter, maka chain code disimpan dalam bentuk string atau untaian karakter. Pada penelitian ini akan digunakan metode pengukuran jarak antara kode rantai dari data training tersimpan dengan kode rantai pada objek yang akan diklasifikasikan menggunakan levenshtein distance. Levenshtein distance merupakan salah satu metode pengukuran jarak antara dua buah string[20][21]. Salah satu keistimewaan levenshtein distance adalah kemampuannya mengenali adanya pengulangan pola string[22].

Algoritma levenshtein distance merupakan algoritma pengukuran jarak antara dua buah string. Algoritma ini melakukan pengukuran sebagai pembanding berdasarkan jumlah operasi penyisipan karakter, penghapusan karakter dan penukaran karakter dalam suatu teks sehingga dapat menyamai teks pembandingnya[23].

Sebagai contoh: suatu teks berisi karakter "berbahagia" dengan teks pembanding berisi karakter "berbahaya" agar teks pertama dapat menyamai teks pembanding, maka teks pertama perlu melakukan penggantian karakter g pada karakter ke 8 menjadi y dan menghapus karakter i pada ke 9 serta menggeser karakter a pada karakter ke 10 ke karakter 9. Dengan demikian terdapat operasi 3 operasi yang dapat membuat teks pertama menjadi sama dengan teks kedua. Jumlah operasi ini lah yang akan dijadikan sebagai skor kemiripan antara dua buah teks tersebut.

$$
\text { SkorKemiripan }=\left(1-\frac{p}{\max (i, j)}\right) \times 100 \%
$$

Rumus Algoritma Levenshtein yang dipergunakan untuk menghitung skor kemiripan diperagakan pada rumus 1 . Variabel $p$ adalah jumlah operasi yang dilakukan agar teks i sama dengan teks $\mathrm{j}$. fungsi max $(\mathrm{i}, \mathrm{j})$ adalah ukuran panjang maksimum antara teks $\mathrm{i}$ dan teks $\mathrm{j}$, dengan demikian teks terpanjang antara teks i dengan teks $\mathrm{j}$ yang akan dipilih untuk menghitung skor kemiripan. Dengan skor kemiripan tertinggi adalah $100 \%$ dan skor kemiripan terendah adalah $0 \%[24]$.

Pengujian akurasi dan kesalahan klasifikasi dihitung berdasarkan rumus (2) dan (3) dari confusion matrix[25][26]. Dimana variabel 1 adalah jumlah kelas, TP adalah jumlah klasifikasi yang benar, TN klasifikasi yang salah, FP adalah klasifikasi yang dikenali sebagai klasifikasi yang lain, sedangkan FN adalah klasifikasi yang dikenali sebagai klasifikasi yang lain. Karena ini merupakan pernghitungan akurasi untuk multiclass, maka setiap hasil akurasi dan hasil error rate pada masing-masing kelas akan dijumlahkan dan dikali dengan $100 \%$.

$$
\begin{aligned}
& \text { Akurasi }=\frac{\sum_{i=1}^{l} \frac{T P_{i}+T N_{i}}{T P_{i}+T N_{i}+F P_{i}+F N_{i}+}}{l} \times 100 \% \\
& \text { ErrorRate }=\frac{\sum_{i=1}^{l} \frac{T N_{i}+F N_{i}}{T P_{i}+T N_{i}+F P_{i}+F N_{i}+}}{l} \times 100 \% .
\end{aligned}
$$

\section{METODOLOGI PENELITIAN}

Metode klasifikasi yang digunakan pada pengenalan karakter menggunakan metode Nearest Neighbor. Klasifikasi dilakukan terhadap fitur kode rantainya dengan pengukuran jarak menggunakan levenshtein distance. Penggunaan levenshtein distance bertujuan agar pengulangan kode rantai ataupun pengulangan serangkaian kode rantai secara berurutan dihitung dengan jarak yang sangat kecil. Tujuan dari nilai jarak berulang yang kecil ini agar memperkecil nilai perbedaan ukuran objek untuk karakter aksara yang sesuai. Mengingat karakteristik dari metode levenshtein distance mampu memperkecil jarak jika terjadi pengulangan huruf secara berurutan yang berbeda jumlahnya antara dua buah teks/string.

Penggunaan metode nearest neighbor dimaksudkan agar mempermudah pencarian kelas dari input objek terhadap data training tersimpan saja, serta mempermudah memahami kedekatan jarak objek dengan data training. Pertimbangan hal ini mengingat fokus dari penelitian ini adalah 
penggunaan fitur kode rantai dengan pengukuran jarak dengan levenshtein distance. Sehingga penggunaan metode nearest neighbor mampu menunjukkan secara langsung data training yang terdekat dengan objek yang akan diklasifikasikan.

Proses pencarian kode rantai dilakukan sampai akhirnya didapat kode rantai dari karakter tersebut. Kode rantai akan disimpan pada data set bersama dengan data sampel yang sudah diinput tersebut. Gambar 1 memperagakan urutan proses memunculkan kode rantai dari suatu objek karakter pada sampel. Gambar 1(a) adalah citra asli yang dipanggil, setelah citra dipanggil, dilakukan proses binerisasi menghasilkan citra biner yang diperagakan pada Gambar 1(b). Selanjutnya citra biner di-thinning, menghasilkan citra yang sudah tipis pada Gambar 1(c). Citra dengan objek yang sudah di-thinning dicari kode rantainya. Visualisasi kode rantai jika dipaksakan di gambar mulai dari posisi awal ujung objek akan tampil seperti pada Gambar 1(d). Binerisasi yang digunakan adalah proses binerisasi citra menggunakan thresholding. Proses thresholding melakukan pembatasan nilai Intensitas piksel (pixel intensity value) pada citra untuk menentukan piksel background dan piksel foreground[27].

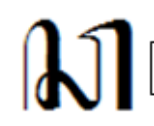

(a)

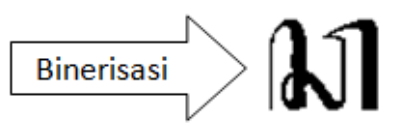

(b)

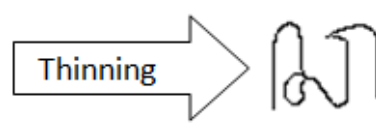

(c)

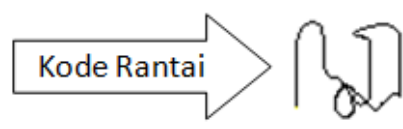

(d)

\section{Gambar 1. Urutan Proses Memunculkan Kode Rantai}

Prioritas arah kode rantai searah jarum jam, mengikuti arah penulisan aksara secara umum. Arah menggunakan 8 arah, agar mampu memfasilitasi garis miring. Prioritas arah dapat dilihat pada Gambar 2. nilai kode rantai dimulai dari 2, karena 0 dan 1 sudah digunakan sebagai nilai pada citra biner. Penentuan nilai kode rantai ini nantinya juga akan dipergunakan sebagai pelabelan, sehingga garis yang sudah dilewati oleh cursor pencari kode rantai tidak akan dipergunakan lagi untuk pelacakan kode rantai. Setiap sel yang sudah dilewati cursor pencari kode rantai akan diganti nilai dengan nilai kode rantai yang didapat.

Proses pencarian kode rantai dilakukan berdasarkan prioritas yang diatur sesuai dengan cara penulisan aksara jawa. Penelusuran kode rantai diperlihatkan pada Gambar 3. Penelusuran dimulai dari ujung objek, pada Gambar peraga ditandai dengan warna kuning. Ujung Objek ini didapat ketika melakukan proses thinning. Jika diperhatikan pada Gambar 3 terdapat perpotongan garis, karena itu kode rantai harus dapat melakukan backtracking ke titik perpotongan semula, sehingga sel yang terlewatkan akibat perpotongan tersebut dapat dilacak ulang setelah cursor pencarian kode rantai sudah berhasil mencapai sel terakhir yang merupakan ujung dari objek.

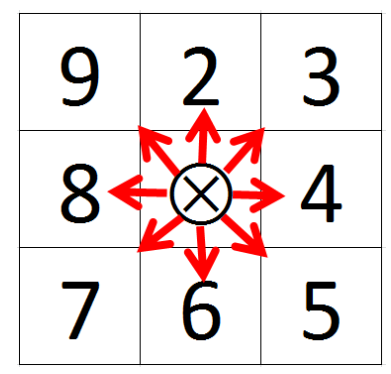

Gambar 2. Prioritas Arah Kode Rantai Yang Dipergunakan

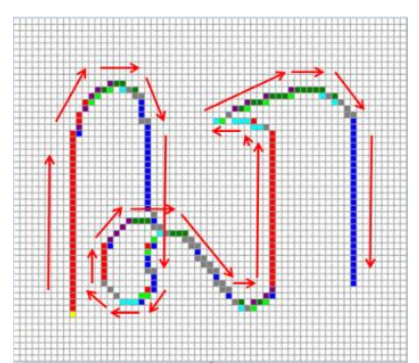

Gambar 3. Contoh Penelusuran Kode Rantai

Input data sampel dimulai dari pengisian data sampel. Field-field data sampel terdiri dari field aksara, field alphabet, field nama, field posisi, dan field bagian. Field aksara menyimpan data simbol karakter dari keyboard yang digunakan untuk menampilkan aksara jawa dari Font Hanacaraka. Data karakter keyboard dan karakter aksara jawa yang dihasilkan terlampir pada lampiran. Secara lengkap field-field penyimpan data sampel dapat dilihat pada Gambar 4. yang merupakan struktur field dari bufDataSet yang dipergunakan untuk menyimpan data sampel. 
Field Posisi untuk menyimpan posisi karakter tersebut. Ada enam nilai, mulai nilai 0 untuk Pangkon, nilai 1 untuk posisi di atas, nilai 2 untuk posisi utama, nilai 3 untuk posisi bawah, nilai 4 untuk karakter taling, dan nilai 5 untuk karakter tarung.

\begin{tabular}{|c|c|c|}
\hline \multicolumn{3}{|c|}{ 20 Edit Fields ... - BufDataset1 } \\
\hline क् $\square$ & 돈 & i $\quad \mathbb{b}$ \\
\hline \multicolumn{3}{|c|}{$\begin{array}{l}\text { idAksara } \\
\text { Aksara } \\
\text { Alphabet } \\
\text { Nama } \\
\text { Oosisi } \\
\text { Bagian } \\
\text { KodeRantai } \\
\text { KodeRantai2 } \\
\text { Kara }\end{array}$} \\
\hline
\end{tabular}

\section{Gambar 4. Field-field penyimpan Data Sampel}

Selanjutnya ada field bagian untuk menyimpan jumlah sub-objek karakter. Hanya ada empat karakter pada aksara jawa yang memiliki dua sub-objek yang terpisah yaitu aksara 'nya', 'ba', 'tha' dan 'nga', bentuk dari aksara tersebut dapat dilihat pada gambar 5. Kode rantai disimpan pada field KodeRantai. Karakter yang memiliki dua sub-objek akan memiliki dua kode rantai, arena itu untuk kode rantai sub-objek kedua disediakan field KodeRantai2. Field Jarak diperlukan untuk menyimpan proses pemilihan karakter dengan jarak terpendek. Nantinya setiap didapatkan satu objek yang akan dicari karakternya nilai jarak nya akan disimpan pada semua field jarak pada masing-masing record data sampel. Kemudian dicari nilai yang terkecil untuk menentukan karakter yang akan dipilih.

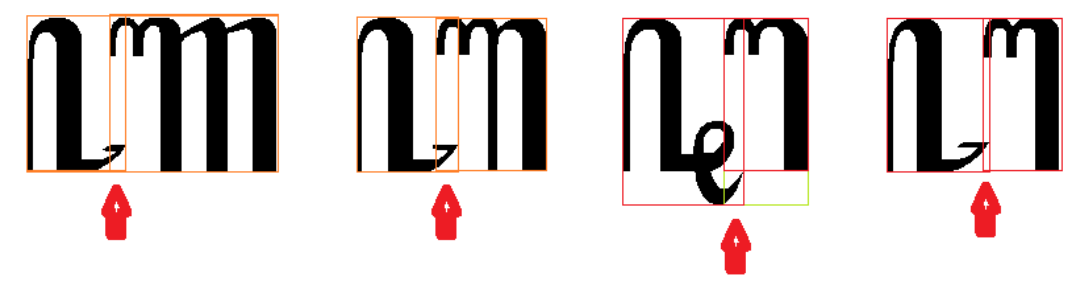

Gambar 5. Aksara 'nya', 'ba', 'tha' Dan 'nga'

Setelah file citra karakter jawa di-drag ke program, maka program akan melakukan proses binerisasi, dilanjutkan proses thinning, sambil melakukan penghitungan jumlah bagian objek yang akan disimpan pada data set. Proses thinning akan menghasilkan alamat sel dari ujung pertama masing-masing objek yang ditemukan. Batas terkiri objek disimpan pada field dengan notasi objek[].x. Batas terkanan masing-masing objek disimpan pada field dengan notasi objek[].k. Implementasi proses thinning yang dipergunakan secara lengkap belum dapat dijelaskan pada artikel ini, karena merupakan proses penelitian dari penulis yang sedang disempurnakan. Alamat sel ujung objek pada masing-masing objek akan menjadi awal pencarian kode rantai pada masing-masing objek. Batas kiri dan batas kanan akan dipergunakan pada penentuan spasi.

Aksara Jawa memiliki aksara yang berisi dua sub Objek yang terpisah, ini terjadi pada aksara 'nya', 'ba', 'tha' dan 'nga'. Aksara ini dapat dilihat pada Gambar 5. Untuk itu pada proses pengumpulan data sampel ini diperlukan proses pelacakan terhadap dua objek terhadap citra input, dan menghasilkan dua kode rantai. Untuk penyimpanannya dua kode rantai tersebut akan disimpan pada dua field yang terpisah sebagai field KodeRantai yang menyimpan kode rantai subobjek pertama dan field kodeRantai2 menyimpan kode rantai sub-objek kedua. Aksara jawa pungkasan hanya memiliki paling banyak dua sub-objek. Hanya keempat aksara ini yang memiliki dua sub-objek. Aksara 'nya', 'ba' dan ;nga' memilik sub-objek pertama yang sama, dengan sub-objek kedua yang berbeda. Aksara 'tha' memiliki sub-objek pertama yang berbeda dari ketiga aksara lainya, tetapi memiliki sub-objek kedua yang sama dengan aksara 'nga'.

Proses pengenalan karakter dapat dilihat pada Gambar 6. Proses pengenalan karakter secara garis besar terdiri dari input citra, proses binerisasi dengan thresholding, proses penipisan 
objek-objek atau thinning, proses pencarian ujung tiap-tiap objek yang dilakukan bersamaan dengan proses thinning, proses pencarian kode rantai yang dimulai dari koordinat ujung-ujung tiap objek. Hasil pencarian kode rantai adalah string teks atau untaian kode rantai yang akan di ukur jaraknya terhadap masing-masing kode rantai dari sampel kode rantai dari aksara yang tersimpan pada Buffer Data Set.

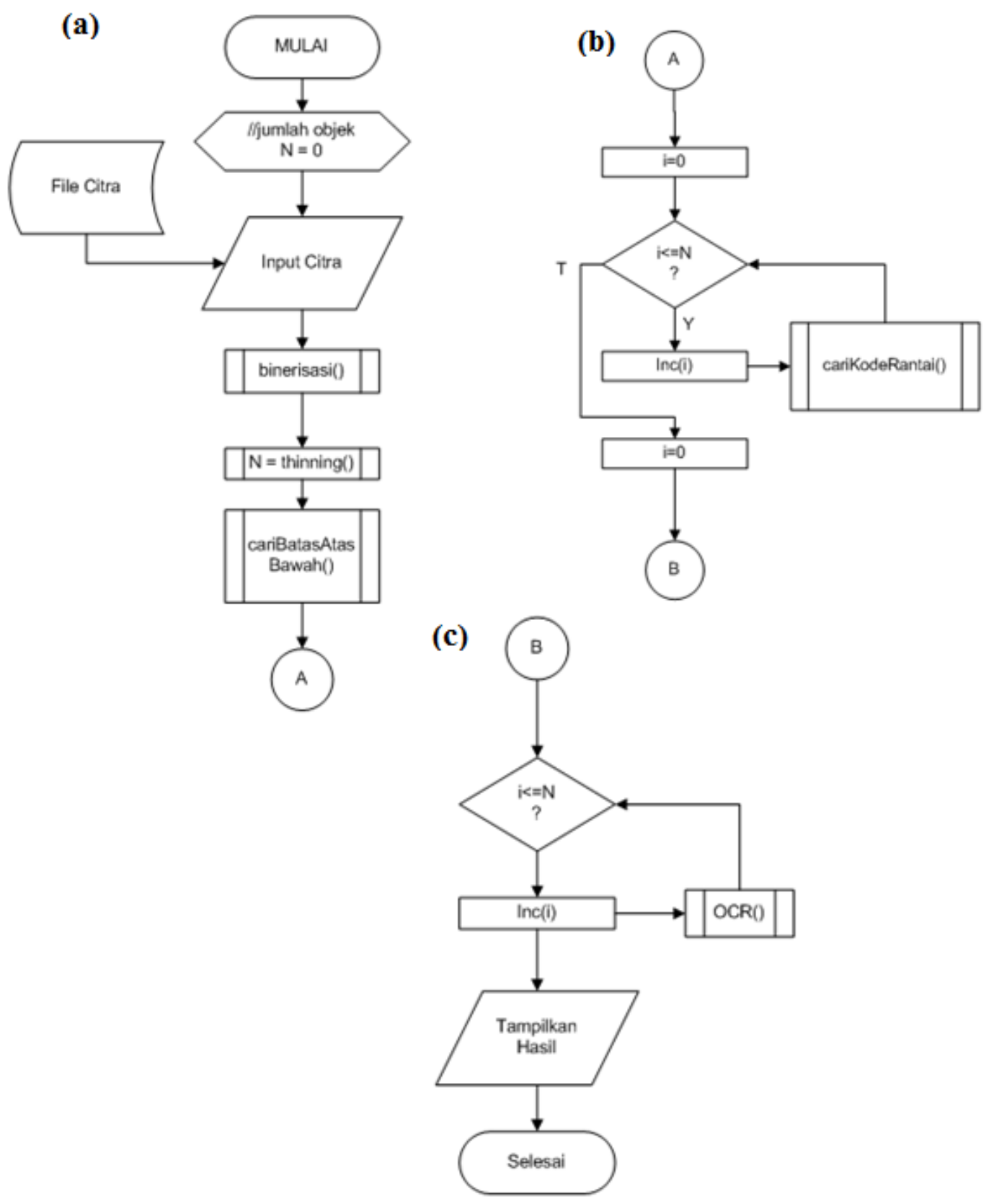

Gambar 6. Proses Pengenalan Karakter

Pencarian batas atas dan bawah dilakukan sebelum mencari kode rantai. Pencarian ini dilakukan setelah melakukan proses thinning. Alasan dilakukan setelah proses thinning karena pada saat proses thinning selesai dilakukan maka batas atas dan bawahnya lebih jelas mengingat untuk tiap guratan hanya setebal satu piksel. Setelah penyusunan frekuensi tiap baris sudah selesai dilakukan, maka kita juga mendapatkan nilai baris dengan frekuensi nilai 0 yang terbanyak dan baris yang menyimpan nilai terbanyak tersebut. Berdasarkan posisi baris tersebut dilakukan pencarian baris sesudah baris yang tidak berisi frekuensi kemunculan nilai 0 sama sekali. Baris yang didapatkan tersebut yang akan menjadi batas Atas. Setelah mendapatkan baris Atas, dilakukan pencarian batas bawah. Pencarian batas bawah dilakukan dengan kondisi baris di atas 
baris dengan frekuensi kemunculan nilai separuh dari rata-rata. Pencarian ini dilakukan dengan asumsi ada aksara yang disertai pasangan tersambung berupa suku atau pengkal, ataupun aksara utama yang memiliki pangkon. Hasil dari pencarian kode rantai berupa serangkaian karakter ' 2 ', '3', '4', '5', '6', '7', '8' dan '9' yang tersimpan pada field koderantai yang bertipe data string. Kode rantai yang tersimpan akan dipergunakan untuk mencari kesamaan objek aksara yang dicari terhadap objek aksara yang tersimpan pada data pembelajaran.

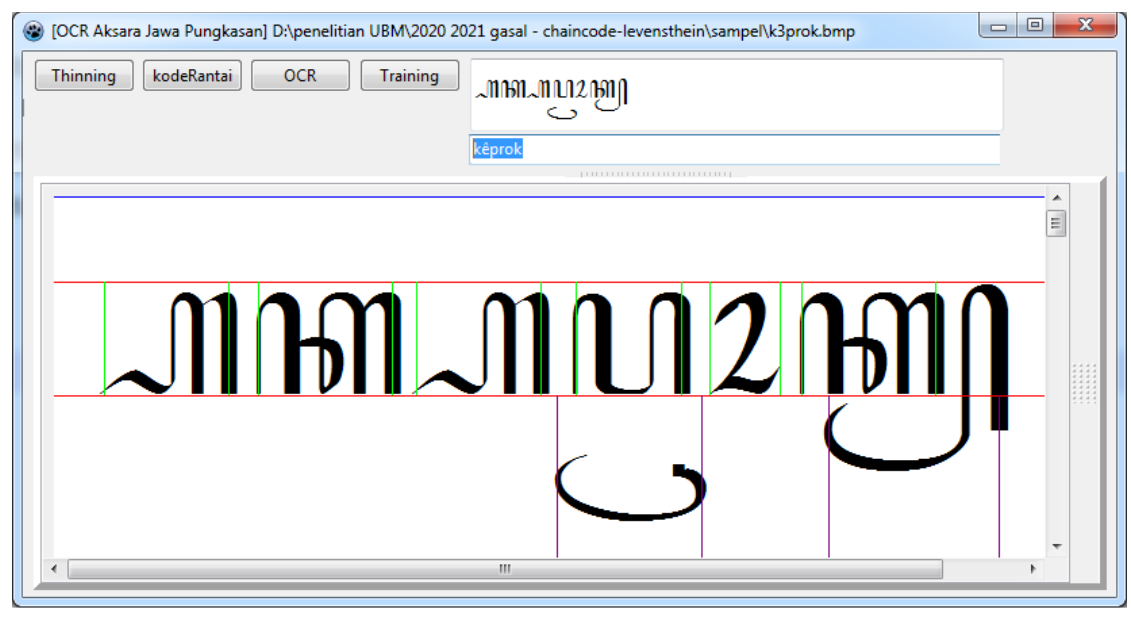

Gambar 7. Tampilan Form

Tampilan form OCR dapat dilihat pada Gambar 7. Button "Thinning” untuk melakukan proses thinning terhadap objek citra. Button "kodeRantai" untuk mencari "kode rantai", Button OCR untuk melakukan penghitungan jarak dan melakukan pencarian jarak terdekat dengan data pelatihan. Button "Training" untuk melakukan penyimpanan terhadap data pelatihan. Aksara jawa hasil OCR ditampilkan pada editBox pertama, romanisasi hasil OCR ditampilkan pada editBox kedua. Sedangkan citra yang dipanggil ditampilkan pada kanvas citra dalam scrollBox.

\section{PENGUJIAN DAN PEMBAHASAN}

Pengujian dilakukan pada kondisi: huruf tegak dan huruf miring. Pengujian dengan kondisi Huruf tegak dilakukan terhadap dua kondisi yaitu huruf tegak yang tinggi dan huruf tegak yang pendek. Pengujian terhadap huruf yang miring dilakukan terhadap huruf miring yang tinggi dan huruf miring yang pendek. Semua huruf menggunakan huruf cetak. Jumlah data set untuk data pembelajaran adalah dua kali jumlah karakter aksara jawa. Aksara yang digunakan adalah adalah aksara jawa pungkasan yang terdiri dari 20 aksara dasar dan 12 pasangan. Jadi total data pembelajaran adalah 66 karakter yang terdiri dari 32 untuk yang huruf miring dan 32 untuk huruf tegak. Jumlah kelas adalah 32. Masing-masing karakter tegak dan karakter lurus pada data pembelajaran hanya diinput satu sampel saja, hal ini dimaksudkan untuk menguji apakah levenshtein distance benar-benar dapat dipergunakan pada fitur kode rantai.

wa dimampatkan kesamping

0222222222222222222222222222222222222222222222222222322233444455565666666666666666666666

6666666666666666666666666665455444444343333232222222222222222222222222222222222222228282

8922334343434444566666666666666666666666666666666666666666666666666666697777776786677778 99987766

Data Tersimpan

id 14 huruf pa jarak 12

0222222222222222222222222222222222233344454556666666666666666666666666666665545445444444

443333222222222222222222222222222232343444545566666666666666666666666666666666998776677

78889998766

id 19 huruf wa jarak 12

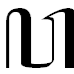

0222222222222222222222222222222222233434454555666666666666666666666666666665554444444444 344332222222222222222222222222829933444344444445666666666666666666666666666666669777886 778999887776

Gambar 8. Citra 'pa' dan 'wa' yang memiliki kode rantai yang hampir sama 
Pengujian dilakukan dengan dua cara, yaitu pengujian data pelatihan menggunakan huruf dasar yang menjadi data pelatihan untuk memastikan pelatihan berhasil pengujian untuk mengukur akurasi klasifikasi. Pengujian yang lain adalah pengujian aplikasi, seperti yang diperagakan pada Gambar 7. Data uji tidak dibuat cacat pada karakternya karena hanya dimaksudkan untuk menguji apakah fitur kode rantai dengan pengukuran jarak levenshtein distance mampu mengatasi perbedaan ukuran font.

Proses pengujian sistem dilakukan dengan cara memasukkan secara acak citra berisi karakter-karakter huruf jawa. Setiap citra berisi 4 sampai 10 karakter termasuk huruf dasar dan pasangan termasuk pangkon. Ukuran citra uji bervariasi secara acak. Semua didapat dari capture dari preview editor ms word yang dicapture perkata. Pengujian dari 100 citra berisi kata dengan aksara jawa menghasilkan $92 \%$ citra berhasil dibaca aksara nya dengan benar dan $8 \%$ citra masih mengalami kesalahan pembacaan dengan adanya aksara yang salah dibacanya. Pengujian ini bukan pengujian akurasi, tetapi hanya pengujian keberhasilan program melakukan OCR dengan benar. Pengukuran keberhasilan ditentukan berdasarkan persentase jumlah huruf dalam satu citra yang berhasil dikenali dengan baik. Semua hasil dihitung rata-rata persentase keseluruhan kondisi pengujiannya. Keberhasilan pada aksara tegak lurus yang diuji per satu karakter dengan kondisi aksara yang diperbesar atau diperkecil adalah 98\%. Setiap karakter diuji dengan 3 perlakuan karakter, diperbesar, diperkecil dan tanpa perubahan skala. Berdasarkan perhitungan akurasi pada seperti pada rumus (2) didapatkan nilai akurasi 98\%. Kesalahan hanya terjadi pada pengenalan aksara 'pa' yang sering dikenali sebagai 'wa', aksara 'nga' yang dikenali sebagai aksara 'nya', serta aksara 'da' ang dikenali sebagai 'na'. Berdasarkan perhitungan error seperti pada rumus (3) didapatkan nilai kesalahan adalah $2 \%$.

Setelah diperiksa ulang dengan cara memotong aksara tersebut dan menginputkan sebagai data uji, ternyata dikarena aksara yang dikenali memiliki kode rantai yang hampir sama dengan aksara yang diharapkan. Ilustrasi ini dapat dilihat pada Gambar 8., menunjukkan citra karakter 'pa' dan 'wa' yang memiliki kode rantai yang hampir sama sehingga ketika citra 'wa' yang dimampatkan kesamping diinput dikenali sebagai citra 'pa'. Hasil pengujian ini dapat dilihat pada Tabel 1. Peraga pada gambar 8 menunjukkan kedua data pelatihan memiliki jarak yang sama dengan data input yaitu 12. Tetapi karena pada pelatihan citra 'pa' di masukkan terlebih dahulu, maka citra 'pa' yang dianggap sebagai data pelatihan yang terdekat. Kesalahan ini terjadi karena metode yang dipergunakan adalah KNN dengan nilai $\mathrm{K}=1$. Ketidaksesuaian hasil disebabkan data pelatihan yang memiliki fitur yang hampir sama. Gambar 8, di bawah setiap objek aksara disertakan kode rantainya untuk menunjukkan kemiripan kode rantainya.

Tabel 1. Tabel Hasil Pengujian

\begin{tabular}{|c|c|c|}
\hline \multirow{2}{*}{ Pengujian } & \multicolumn{2}{|c|}{ Style Aksara } \\
\cline { 2 - 3 } & tegak & Italic \\
\hline \hline Data Pelatihan & $100 \%$ & $100 \%$ \\
\hline Keberhasilam Uji Aplikasi & $92 \%$ & $42 \%$ \\
\hline Uji Akurasi & $98 \%$ & Tidak Diuji \\
\hline Uji Error & $2 \%$ & Tidak Diuji \\
\hline
\end{tabular}

Hasil pengujian menunjukkan bahwa pengukuran jarak menggunakan levenshtein distance cukup efektif untuk mengukur jarak terhadap dua kode rantai pada dua aksara dengan objek yang tegak dan ukuran yang berbeda. Karena sifat dari levenshtein distance yang akan mentoleransi adanya bagian string yang berulang. Sehingga meskipun aksara dipendekkan atau ditinggikan, tetap dapat dikenali sebagai aksara yang sama. Kegagalan terjadi pada pengenalan aksara yang memiliki bentuk yang hampir sama. Ketidak berhasilan terjadi pada aksara huruf miring yang berbeda ukuran dengan citra pelatihan. Pada Tabel 1 dilaporkan nilai aksara yang dikenali hanya sekitar $42 \%$. Ketidak berhasilan ini dikarenakan adanya kode rantai yang dihasilkan berbeda. Garis miring yang dipendekkan atau ditinggikan akan membentuk substring 
yang berbeda susunannya. Pola kode rantai yang berubah yang mengakibatkan pengenalan huruf mengalami kekeliruan. Karena keberhasilan pada pengujian aksara dengan style italics sangat kecil, maka tidak dilakukan pengujian akurasi lagi.

\section{KESIMPULAN}

Kode Rantai dengan menggunakan algoritma Levenshtein Distance sebagai pengukuran jaraknya dapat digunakan untuk mengenali karakter aksara jawa dari citra yang berbeda ukuran pada huruf dengan style tegak, dengan keberhasilan 98\%. Kemampuan pengukuran jarak pada algoritma levenshtein distance untuk mengukur jarak terhadap kode rantai dari dua citra objek aksara jawa yang berbeda ukuran disebabkan oleh kemampuan algoritma levenshtein distance untuk mengenali adanya pengulangan karakter secara berurutan ataupun serangkaian karakter yang berurutan sehingga memperkecil pertambahan nilai jaraknya.

Kode Rantai dengan menggunakan algoritma Levenshtein Distance sebagai pengukuran jaraknya dapat digunakan untuk mengenali karakter aksara jawa dari citra yang berbeda ukuran pada huruf dengan style italic / miring, belum berhasil karena hanya memiliki keberhasilan $42 \%$, karena itu diperlukan perlakuan tambahan agar kemiringan tidak mempengaruhi secara signifikan hasil jaraknya. Masalah ini akan dijadikan penelitian berikutnya.

\section{Daftar Pustaka}

[1] B. Setiawan, P. Wibowo, F. Azzahrah, P. Harjani, and K. Saddhono, "Study of Javanese Script Writing Learning in Senior High Schools in Boyolali Regency,” 2019, doi: 10.4108/eai.29-8-2019.2288906.

[2] E. K. Aribowo, "Digitalisasi Aksara Jawa Dan Pemanfaatannya Sebagai Media Pembelajaran Bagi Musyawarah Guru Mata Pelajaran Bahasa Jawa Smp Kabupaten Klaten," War. LPM, vol. 21, no. 2, pp. 59-70, Jun. 2018, doi: 10.23917/warta.v21i2.5620.

[3] I. A. Persada, "Pengaruh penggunaan aplikasi hanacaraka terhadap hasil belajar kognitif aksara jawa kelas 4 sd negeri giwangan yogyakarta the effectiveness of hanacaraka apps toward cognitive students' learning result in grade 4 of sd negeri giwangan yogyakarta.," E-Jurnal Skripsi Progr. Stud. Teknol. Pendidik., vol. VI, no. 1, pp. 35-42, 2017, [Online]. Available: http://journal. student.uny.ac.id/ojs/index.php/fiptp/article/view/6107.

[4] A. M. Setiawan, Agus, Sulaiman, "Hanacaraka: Aksara Jawa Dalam Karakter Font dan Aplikasinya Sebagai Brand Image," Ornamen, vol. 12, no. 01, p. 33=47, 2015, [Online]. Available: https://jurnal.isi-ska.ac.id/index.php/ornamen/article/view/1609.

[5] D. Nurhayati and D. I. Abdurrahman, "Upaya Revitalisasi Aksara Jawa Hanacaraka Melalui Media T-Shirt,” J. Atrat, vol. 6, 2018, [Online]. Available: https://jurnal.isbi.ac.id/index.php/atrat/article/view/661.

[6] R. Agustian, N. A. H., and J. Karel, "Implementasi Metode Chain Code Untuk Pengenalan Rambu Lalu Lintas,” J. Inform., vol. 12, no. 1, pp. 67-75, 2016, doi: 10.21460/inf.2016.121.413.

[7] M. A. M. Andy Haryoko, Sholeh Hadi Pramono, "Pengenalan Karakter Plat Kendaraan Bermotor Berbasis Citra Dengan Menggunakan Metode Canny Dan Algoritma Backpropagation," Netw. Eng. Res. Oper., vol. 2, no. 2, pp. 123-130, 2016, doi: http://dx.doi.org/10.21107/nero.v2i2.57.

[8] S. Mawaddah and N. Suciati, "Pengenalan Karakter Tulisan Tangan Menggunakan Ekstraksi Fitur Bentuk Berbasis Chain Code," J. Teknol. Inf. dan Ilmu Komput., vol. 7, no. 4, p. 683, Aug. 2020, doi: 10.25126/jtiik.2020742022.

[9] T. F. Abidin, A. A. AzZuhri, and F. Arnia, "Pengenalan Karakter Plat Nomor Kendaraan Bermotor Menggunakan Zoning dan Fitur Freeman Chain Code," J. Rekayasa Elektr., vol. 14, no. 1, pp. 19-25, Apr. 2018, doi: 10.17529/jre.v 14i1.8932.

[10] S. Styawati and K. Mustofa, "A Support Vector Machine-Firefly Algorithm for Movie Opinion Data Classification," IJCCS (Indonesian J. Comput. Cybern. Syst., vol. 13, no. 3, p. 219, Jul. 2019, doi: 10.22146/ijccs.41302.

[11] D. R. Anamisa, "Aplikasi Segmentasi Objek Menggunakan Cellular Neural Network ( Cnn )," Netw. Eng. Res. Oper., vol. 1, no. 3, pp. 157-163, 2015, doi: 
http://dx.doi.org/10.21107/nero.v1i3.40.

[12] Y. S. Safitri Juanita, "Pengembangan Aplikasi Text Recognition Dengan Klasifikasi Neural Network Pada Huruf Aksara Jawa," Telemat. MKOM, vol. 5, no. 2, pp. 290-296, 2013, [Online].

Available: https://journal.budiluhur.ac.id/index.php/telematika/article/view/99.

[13] T. M. S. Mulyana and A. Harjoko, "A chinese character recognition method based on population matrix and relational database," Proc. 2nd Int. Conf. Inf. Commun. Technol. Semin. ICTS 2006, no. 1, pp. 518-523, 2006.

[14] R. Agustian, N. A. H., and J. Karel, "Implementasi Metode Chain Code Untuk Pengenalan Rambu Lalu Lintas" J. Inform., vol. 12, no. 1, Jun. 2016, doi: 10.21460/inf.2016.121.413.

[15] S. Sanjaya, M. L. Pura, S. K. Gusti, F. Yanto, and F. Syafria, "K-Nearest Neighbor for Classification of Tomato Maturity Level Based on Hue, Saturation, and Value Colors," Indones. J. Artif. Intell. Data Min., vol. 2, no. 2, p. 101, Nov. 2019, doi: 10.24014/ijaidm.v2i2.7975.

[16] S. Wiyono and T. Abidin, "Implementation Of K-Nearest Neighbour (Knn) Algorithm To Predict Student's Performance," Simetris J. Tek. Mesin, Elektro dan Ilmu Komput., vol. 9, no. 2, pp. 873-878, Nov. 2018, doi: 10.24176/simet.v9i2.2424.

[17] H. A. Abu Alfeilat et al., "Effects of Distance Measure Choice on K-Nearest Neighbor Classifier Performance: A Review," Big Data, vol. 7, no. 4, pp. 221-248, Dec. 2019, doi: 10.1089/big.2018.0175.

[18] K. Chomboon, P. Chujai, P. Teerarassammee, K. Kerdprasop, and N. Kerdprasop, "An Empirical Study of Distance Metrics for k-Nearest Neighbor Algorithm," in The Proceedings of the 2nd International Conference on Industrial Application Engineering 2015, 2015, pp. 280-285, doi: 10.12792/iciae2015.051.

[19] T. Cover and P. Hart, "Nearest neighbor pattern classification," IEEE Trans. Inf. Theory, vol. 13, no. 1, pp. 21-27, Jan. 1967, doi: 10.1109/TIT.1967.1053964.

[20] E. S. Ristad and P. N. Yianilos, "Learning string-edit distance," IEEE Trans. Pattern Anal. Mach. Intell., vol. 20, no. 5, pp. 522-532, May 1998, doi: 10.1109/34.682181.

[21] R. Umar, Y. Hendriana, and E. Budiyono, "Implementation of Levenshtein Distance Algorithm for ECommerce of Bravoisitees Distro," Int. J. Comput. Trends Technol., vol. 27, no. 3, pp. 131-136, Sep. 2015, doi: 10.14445/22312803/IJCTT-V27P123.

[22] T. Ho, S.-R. Oh, and H. Kim, "A parallel approximate string matching under Levenshtein distance on graphics processing units using warp-shuffle operations," PLoS One, vol. 12, no. 10, p. e0186251, Oct. 2017, doi: 10.1371/journal.pone.0186251.

[23] D. S. Hirschberg, "A linear space algorithm for computing maximal common subsequences," Commun. ACM, vol. 18, no. 6, pp. 341-343, Jun. 1975, doi: $10.1145 / 360825.360861$.

[24] D. Rosmala and Z. M. Risyad, "Algoritma Levenshtein Distance dalam Aplikasi Pencarian isu di Kota Bandung pada Twitter," MIND J., vol. 2, no. 2, pp. 1-12, Nov. 2018, doi: 10.26760/mindjournal.v2i2.1-12.

[25] A. A. Arifiyanti, R. M. Pradana, and I. F. Novian, "Klasifikasi Produk Retur dengan Algoritma Pohon Keputusan C4.5," J. IPTEK, vol. 22, no. 1, p. 79, May 2018, doi: 10.31284/j.iptek.2018.v22i1.243.

[26] C. Manliguez, "Generalized Confusion Matrix for Multiple Classes." 2016, doi: 10.13140/RG.2.2.31150.51523.

[27] T. M. S. Mulyana and Herlina, "Evenly brightening using kurtosis Gaussian pattern to simplify image binarization," J. Phys. Conf. Ser., vol. 1397, no. 1, p. 012076, Dec. 2019, doi: 10.1088/1742-6596/1397/1/012076. 